\title{
Morphometric Study of Plantaris Muscle in South Indian Population and its Clinical Importance
}

\author{
Rahul Jain ${ }^{1}$, Radhika P.M. ${ }^{2 *}$, Shailaja Shetty ${ }^{3}$
}

Section: Healthcare

Sci. Journal Impact

Factor: 6.1 (2018)

ICV: 90.90 (2018)

Scopus'

\author{
Intern, M.S. Ramaiah Medical College, Bangalore; 'Assistant Professor, Department of Anatomy, M.S. Ramaiah Medical College, Bangalore; \\ ${ }^{3}$ Professor \& HOD, Department of Anatomy, M.S. Ramaiah Medical College, Bangalore.
}

\section{ABSTRACT}

Background: The plantaris has a small belly with a thin slender tendon in the posterior compartment of leg. It's a vestigial muscle which has gained importance because of its use in tendon grafting. It arises from lateral supracondylar ridge of femur and gets inserted into tendoachillis. It is innervated by tibial nerve and contributes in flexion of knee joint and plantar flexion of the ankle.

Aim: The aim of study is to determine origin, insertion length of the muscle belly, length of the tendon inside the muscle belly, width of the tendon and total length of the tendon of plantaris muscle in south Indian population.

Materials and Method: The present study was carried out on 50 lower extremities from formalin-fixed cadavers irrespective of age, sex and race in the Department of Anatomy, M.S.Ramaiah Medical College. Details of the morphometric measurements of plantaris muscle such as length of the muscle belly, length of the tendon inside the muscle belly, width of the tendon and total length of the tendon, and anatomical variations were noted and measured with a digital vernier caliper, appropriate photographs were taken and results were tabulated after statistical analysis..

Results: In present study, frequency of plantaris muscle is $88.46 \%$ in left and $91.66 \%$ in right . Themean length of muscle belly was $9.444 \mathrm{~cm}$ and mean muscle belly width was $1.944 \mathrm{~cm}$ and total tendon length was $38.028 \mathrm{~cm}$ and width of tendon was $0.3549 \mathrm{~cm}$.

Conclusion: The knowledge of morphometric measurements of plantaris muscle is of importance to radiologists, physiotherapists, orthopaedicians, plastic surgeons, clinicians because of use of muscle tendon in reconstructions, diagnosing muscle tears, MRI intepretation, repair of Atrioventricular valves and muscle injuries.

Key Words: Plantaris, Morphometry, Tendon grafting

\section{INTRODUCTION}

Plantaris is a small muscle with short belly and a long thin tendon present in the posterior compartment of the leg and soleus and gastrocnemius. It originates from lower part of the lateral supracondylar line and the oblique popliteal ligament and inserts commonly into posterior surface of the calcaneum. It is innervated by tibial nerve which is a branch of sciatic nerve. Its actions mainly include plantar flexion in the posterior compartment of the leg, along with the gastrosoleus ${ }^{1}$. Plantaris even though a vestigial muscle, is rich in proprioceptive fibres ${ }^{2}$. As reported in literature it may be absent in 7-20\% cases $^{3}$; sometimes, it may be appears as dual heads. Besides its minor contribution to mobility, it still has wide clinical and diagnostic importance.
In a study done by Nayak $\mathrm{Sr}$ et al.., plantaris muscle was classified into 3 types depending on origin. Type I-arising from Lateral supracondylar ridge,capsule of knee joint and lateral head of gastrocnemius was seen in $73.07 \%$ cases, In Type II origin is from capsule of knee joint and the lateral head of gastrocnemius in $5.76 \%$ cases, Type III origin is from Lateral supracondylar ridge, capsule of knee joint, lateral head of gastrocnemius and fibular collateral ligament in $13.46 \%$ cases $^{4}$.

The plantaris was also classified based on types of insertion which were, Type I-insertion to the flexor retinaculum of the foot in $28 \%$ of cases, Type II-insertion independently to the calcaneum in $36.53 \%$ cases, Type III-insertion to the tendocalcaneus at various levels in $26.92 \%$ cases $^{4}$.

\section{Corresponding Author:}

Dr. Radhika P.M., Assistant professor, Department of Anatomy, M.S. Ramaiah Medical College, MSRIT Post Bangalore 560054, India. Phone: 9035044023; E-mail: parameshradhika@gmail.com

ISSN: 2231-2196 (Print)

Received: 14.05 .2020
ISSN: $0975-5241$ (Online)

Revised: 10.06 .2020
Accepted: 22.06 .2020 
In a study done by Nazeer et al.., plantaris muscle insertion were classified into 5 types described Type I-insertion to calcaneum medial to Achilles tendon, Type II-insertion as Fan shaped expansion superficial to the Achilles tendon, Type III-insertion as Fan shaped expansion deep to Achilles tendon, Type IV-insertion as Fan shaped expansion deep to Achilles tendon and flexor retinaculum, Type $\mathrm{V}$ insertion with Achillis tendon to the calcaneum 5 .

In hand surgeries early mobilization is keystone for good outcome, on contrary, early mobilization may rupture the repair at either end of graft. It has been recently published in a article using plantaris with a bone peg as a secondary reconstruction source, since bone to bone attachment occurs quicker than bone to tendon grafts; therefore, this benefits post operative movements and limits adhesions warranting early recovery ${ }^{6-8}$.

The study aims to determine muscle belly, length of the tendon inside the muscle belly, width of the tendon, and total length of the tendon of plantaris muscle in South Indian population. The tendon of the plantaris muscle can be used for reconstruction of hand tendons, Reconstruction of lateral ankle ligament, Repairs of atrioventricular valves ${ }^{9}$.

The study is important for physiotherapists, plastic surgeons performing tendon transfer operations, clinicians diagnosing muscle tears and radiologists interpreting MRI scans ${ }^{10}$.

\section{MATERIAL AND METHODS}

The present study was carried out on 50 lower extremities from formalin-fixed cadavers irrespective of age, sex and race in the Department of Anatomy, M.S.Ramaiah Medical College. Dissection of the posterior compartment of leg and popliteal fossa was done and origin and insertion of plantaris were identified. Each specimen was marked and was given number. Details of the morphometric measurements of plantaris muscle such as length of the muscle belly, length of the tendon inside the muscle belly, width of the tendon and total length of the tendon, and anatomical variations were noted and measured with a digital vernier caliper, appropriate photographs were taken and results were tabulated after statistical analysis.

\section{RESULTS}

The plantaris muscle was dissected in 50 limbs. Thestatistical analysis was carried out and tabulated. The frequency of presence and absence of plantaris muscle was tabulated in table 1 and fig 1 . In the present study, three Types of origin and five types of insertion were tabulated(table 2 and 3 ). The mean length, width of plantaris muscle and tendon were tabulated.(table 4). In one specimen the plantaris had dual origin (fig 2).
Table 1: Frequency of Occurrence of Plantaris Muscle

\begin{tabular}{llcc} 
Side & & Frequency & Percent \\
Left & Absent & 3 & $11.53 \%$ \\
& Present & 23 & $88.46 \%$ \\
\multirow{3}{*}{ Right } & Total & 26 & $100 \%$ \\
& Absent & 2 & $8.33 \%$ \\
& Present & 22 & $91.66 \%$ \\
& Total & 24 & $100 \%$ \\
\hline
\end{tabular}

Table 2: Frequency and percentage of origin of plantaris muscle

\begin{tabular}{lcc} 
& Frequency & Percent \\
Additional origin from gastrocnemius & 6 & $13.33 \%$ \\
$\begin{array}{lcc}\text { Bifid(additional origin from gastroc- } \\
\text { nemius) }\end{array}$ & 1 & $\mathbf{2 . 2 2} \%$ \\
Normal & 38 & $84.44 \%$ \\
Total & 45 & $100 \%$ \\
\hline
\end{tabular}

Table 3: Frequency and percentage of insertion of plantaris

\begin{tabular}{lcc} 
& Frequency & Percent \\
$\begin{array}{l}\text { Insertion to calcaneum medial to } \\
\text { achillis tendon(type 1) }\end{array}$ & 35 & $77 \cdot 77 \%$ \\
$\begin{array}{l}\text { Insertion as fan-shaped expansion su- } \\
\text { perficial to the achillis tendon(type 2) }\end{array}$ & 1 & $\mathbf{2 . 2 2} \%$ \\
$\begin{array}{l}\text { Insertion as fan shaped expansion } \\
\text { deep to achillis tendon(type 3) }\end{array}$ & 8 & $17 \cdot 77 \%$ \\
$\begin{array}{l}\text { Insertionas fan shaped expansion } \\
\text { deep to achillis tendon and flexor } \\
\text { retinaculum(type 4) }\end{array}$ & 1 & $\mathbf{2 . 2 2} \%$ \\
$\begin{array}{l}\text { Insertion with achillis tendon to the } \\
\text { calcaneum (type 5) }\end{array}$ & 0 & $0.00 \%$ \\
\begin{tabular}{l} 
Total \\
\hline
\end{tabular} & 45 & $100 \%$ \\
\hline
\end{tabular}

Table 4: Showing mean values of length, width of muscle belly and tendon.

\begin{tabular}{lcc} 
& Mean & Std Dev. \\
Muscle belly length $(\mathrm{cm})$ & $9.444 \mathrm{~cm}$ & $1.958 \mathrm{~cm}$ \\
Muscle belly width $(\mathrm{cm})$ & $1.944 \mathrm{~cm}$ & $1.461 \mathrm{~cm}$ \\
Tendon inside muscle $(\mathrm{cm})$ & $5.535 \mathrm{~cm}$ & $1.916 \mathrm{~cm}$ \\
Tendon outside muscle $(\mathrm{cm})$ & $32.49 \mathrm{~cm}$ & $2.534 \mathrm{~cm}$ \\
Total tendon $(\mathrm{cm})$ & $38.028 \mathrm{~cm}$ & $3.162 \mathrm{~cm}$ \\
Width of tendon $(\mathrm{cm})$ & $0.3549 \mathrm{~cm}$. & $0.175 \mathrm{~cm}$ \\
Total length $(\mathrm{cm})$ & $41.937 \mathrm{~cm}$ & $3.419 \mathrm{~cm}$ \\
\hline
\end{tabular}

\section{DISCUSSION}

Plantaris muscle is considered as vestigial because of its slender tendon and has a minor contribution to the gastrocnemius and soleus muscle of the posterior compartment with 
which it has been associated. The plantaris joins with triceps surae and plantar flexes the foot through the Achillis tendon. There is growing evidence which suggests, that each of the three muscle has a unique attribute to the overall function of this important muscle group.

The remarkably short and slender plantaris muscle with its long slender tendon serves a proprioceptive function that provides a kinesthetic sense of limb position and muscle contraction. The whole concept of vestigial or functionless muscles is that unused muscles quickly degenerate. It is unlikely that any muscle that was virtually unused for the lifetime of an individual (to say nothing of generations of individuals over millions of years) would remain as healthy muscle tissue 2 .

The results of the present study were compared with other previous study and tabulated (table 5, 6, 7). In the present study, frequency of absence of plantaris was found to more when compared to other studies. The frequency of insertion of plantaris muscle to bone was seen. This can help the surgeons make a decision for use of plantaris with a bone peg. It was seen that the plantaris is attached to the calcaneum in $77.7 \%$ making it an ideal source for tendon grafting.

Table 5: Comparision of frequency of absence of plantaris in present and other studies

\begin{tabular}{|c|c|c|}
\hline Study & Freq of Absence & $\begin{array}{c}\text { Freq of } \\
\text { Absence }\end{array}$ \\
\hline & Left & Right \\
\hline Sangeeta $\mathrm{M}$ et al. ${ }^{9}$ & $\mathrm{o} / 20(0 \%)$ & $\mathrm{o} / 20(0 \%)$ \\
\hline Nazeer et al. ${ }^{10}$ & $01 / 25(04 \%)$ & $01 / 25(04 \%)$ \\
\hline Najma mobin ${ }^{8}$ & $01 / 30(03.33 \%)$ & $01 / 30(03.33 \%)$ \\
\hline Present study & $03 / 26(11.53 \%)$ & $02 / 24(08.33 \%)$ \\
\hline
\end{tabular}

Table 6: Comparison of Frequency and percentage of insertion of plantaris of present study and other study

\begin{tabular}{lcc} 
Types of insertion & $\begin{array}{c}\text { Najma mobin } \\
\text { Frequency \& } \\
\text { percentage }\end{array}$ & $\begin{array}{c}\text { Our study } \\
\text { Frequency \& } \\
\text { percentage }\end{array}$ \\
\hline Type 1 & $38(65.51 \%)$ & $35(77.77 \%)$ \\
Type 2 & $7(12.06 \%)$ & $1(2.22 \%)$ \\
Type 3 & $2(3.44 \%)$ & $8(17.77 \%)$ \\
Type 4 & $4(6.89 \%)$ & $1(2.22 \%)$ \\
Type 5 & $7(12.06 \%)$ & $0(0.00 \%)$ \\
Total & $58(100 \%)$ & $45(100 \%)$ \\
\hline
\end{tabular}

Table 7: Comparision of mean values of length, width of muscle belly and tendon in present study and other studies

\begin{tabular}{lccccc} 
Study & $\begin{array}{c}\text { Muscle } \\
\text { Belly } \\
\text { Length }\end{array}$ & $\begin{array}{c}\text { Tendon } \\
\text { Length }\end{array}$ & $\begin{array}{c}\text { Tendon } \\
\text { Width }\end{array}$ & $\begin{array}{c}\text { Tendon } \\
\text { Inside } \\
\text { Muscle }\end{array}$ & $\begin{array}{c}\text { Total } \\
\text { Tendon } \\
\text { Length }\end{array}$ \\
\hline $\begin{array}{l}\text { Aragao et } \\
\text { al. }\end{array}$ & $11.38 \mathrm{~cm}$ & $33.26 \mathrm{~cm}$ & $0.70 \mathrm{~cm}$ & $5.5 \mathrm{~cm}$ & - \\
$\begin{array}{l}\text { Sangeeta } \\
\text { M et al. }\end{array}$ & $8.15 \mathrm{~cm}$ & $31.31 \mathrm{~cm}$ & $0.537 \mathrm{~cm}$ & $3.52 \mathrm{~cm}$ & - \\
$\begin{array}{l}\text { Nazeer et } \\
\text { al. }{ }^{10}\end{array}$ & $7.99 \mathrm{~cm}$ & $33.16 \mathrm{~cm}$ & $0.30 \mathrm{~cm}$ & - & - \\
$\begin{array}{l}\text { Najma } \\
\text { mobin }\end{array}$ & $11.38 \mathrm{~cm}$ & $33.26 \mathrm{~cm}$ & - & - & $43.25 \mathrm{~cm}$ \\
$\begin{array}{l}\text { Present } \\
\text { study }\end{array}$ & $9.44 \mathrm{~cm}$ & $32.49 \mathrm{~cm}$ & $0.35 \mathrm{~cm}$ & $5.53 \mathrm{~cm}$ & $38.028 \mathrm{~cm}$ \\
\hline
\end{tabular}

Clinically, plantaris tendon is an ideal source for soft tissue augmentation for ligament reconstruction or tendon repair. The plantaris tendon has high tensile strength with structured collagen characteristic of physiologic tendons. Harvest of plantaris tendon rarely creates appreciable donor site morbidity. Plantaris tendon has highest tensile strength $(94 \mathrm{~N} /$ MM3 $)^{11}$. It is also considered as ideal graft due to location in sterile field for every foot and ankle procedure. No arteries, nerves, and veins are present between soleus and gastrocnemius, making it even easier for harvesting ${ }^{12}$.

Ultrasound is useful in identifying the presence of a plantaris tendon and has high specificity. MRI is used to evaluate an injury to an ankle ligament, it can also be used in identifying presence of an ipsilateral plantaris tendon that may be used for tissue augmentation. ${ }^{10}$

Plantaris tendon can be used in AV valve repair. The mitral valve repair is better than mitral valve replacement because prosthetic ring annuloplasty is associated with chronic anticoagulation, suboptimal hemodynamics, and potential infectious complications which can be avoided using plantaris tendon. Normal left ventricular geometry is maintained by retaining the native mitral valve apparatus and annuloplasty can be performed by tendon tissue due to its smooth surface. Splitting or lateral stretching stimulates collagenous adhesions that in theory can impart superior dynamics through an anatomic restoration that surpasses a synthetic restoration. The easy availability of plantaris tendon, in addition, makes it an economic source of material to cover tissue defects after removal of calcified atrioventricular valves, which should contribute plantaris tissue for the particular use in developing countries ${ }^{9}$.

In the present study, dual origin was noted in 6 specimens and in one specimen it was double head. Dual origin plan- 
taris can sometimes gives way to tibial nerve passing in between the two heads and can cause pain in the lower limb due to compression of nerve while walking between the two heads ${ }^{13}$.

\section{CONCLUSION}

Plantaris muscle has a long slender tendon which fuses with superficial fascia of leg, thereby making it vulnerable to injury. The topographical anatomy of plantaris muscle and its resemblance to a nerve should be kept in mind by the surgeons operating on the back of leg. The rupture of tendon is often difficult to diagnose since it is associated with haemorrhage and edema.

In present study plantaris was absent in $10 \%$ of legs which is clinically relevant as plantaris and its tendon have multiple uses in clinical practice. In the present study, morphometric analysis of plantaris was done which is of immense importance to the plastic surgeons performing tendon transfer operations, clinical diagnosing muscle tears and radiologists interpreting MRI scans.

\section{ACKNOWLEDGMENT}

Authors acknowledge the immense help received from the scholars whose articles are cited and included in references of this manuscript. The authors are also grateful to authors / editors / publishers of all those articles, journals and books from where the literature for this article has been reviewed and discussed.

\section{Source of Funding: Nil}

\section{Conflict of interest: None}

\section{REFERENCES}

1. Richard L Drake, A Wayne Vogl, Adam W. M. Mitchell. Gray's Anatomy for Students, $1^{\text {st }}$ South Asia ed. New Delhi: Elsevier; 2017:680.

2. David N. Menton. The Plantaris and the Question of Vestigial Muscles in Man. Journal of Creation. 2000; 14(2):50-53

3. Simpson S L, Hertzog M S, Barja R H. The Plantaris Tendon graft: An Ultrasound Study. Journal Hand Surg July 1999;16(4):708-11

4. Nayak SR, Krishnamurthy A, Ramanathan L, Ranade AV, Prabhu LV, Jiji PJ, Rai R, Chettiar GK, Potu BK. Anatomy of Plantaris Muscle: A study in adult Indians. La clinical Terapeutica2010;161(3):249-252.

5. Nazeer Ahmed, Khwaja Nawazuddin Sarwari. Morphological variations and surgical importance of the plantaris muscle in humans. Indian Journal of Fundamental and Applied Life Sciences ISSN 2013; 3(4):342-346

6. Amadio P, An KN, Ejeskar A, Guimbertau, J Claude, Harris S, Savage R, Stewart K,P., Bo Tang J. IFSSH Flexor Tendon Committee report 2014: from the IFSSH Flexor Tendon Committee. J Hand Surg 2005;30B:100-116

7. Amadio PC, Wood MB, Cooney WP 3rd, Bogard SD. Staged Flexor tendon reconstruction in the Fingers and hand. J Hand Surg1988;139 (4): 559-62

8. Bertelli JA, Santos MA, Kechele PR, Rost JR, Tacca CP. Flexor tendon grafting using a plantaris tendon with a fragment of attached bone for fixation to the distal phalanx: a preliminary cohort study. J Hand Surg 2007;32A:1543-1548.

9. Jeffrey H Shuhaiber and Hans H Shuhaiber. Plantaris Tendon Graft for Atrioventricular Valve Repair. Tex Heart Inst J 2003; 30(1):42-4.

10. Andreo A. Spina. The plantaris Muscle: Anatomy, Injury, Imaging and Treatment. Canada: J Can Chiropr Assocjul-Sept 2007; 51(3):158-165

11. Bohnsackm, Surieb, Kirschil et al. Biomechanical properties of commonly used autogeneous transplants in the surgical treatment of chronic lateral ankle instability. Foot Ankle Int 2002;23:661-664.

12. Geert I Pagenstert, Beat hintermann. Proximal Mini-invasive Grafting of Plantaris Tendon. Campbell's operative orthopaedics. Volume 4,10th edition. Edited by S Terry Canale. St louis:Mosby; 2003:4454-4457.

13. Upasna, Ashwini Kumar. Bicipital origin of Plantaris Muscle A Case Report. International Journal of Anatomical Variations 2011; 4:177-179.

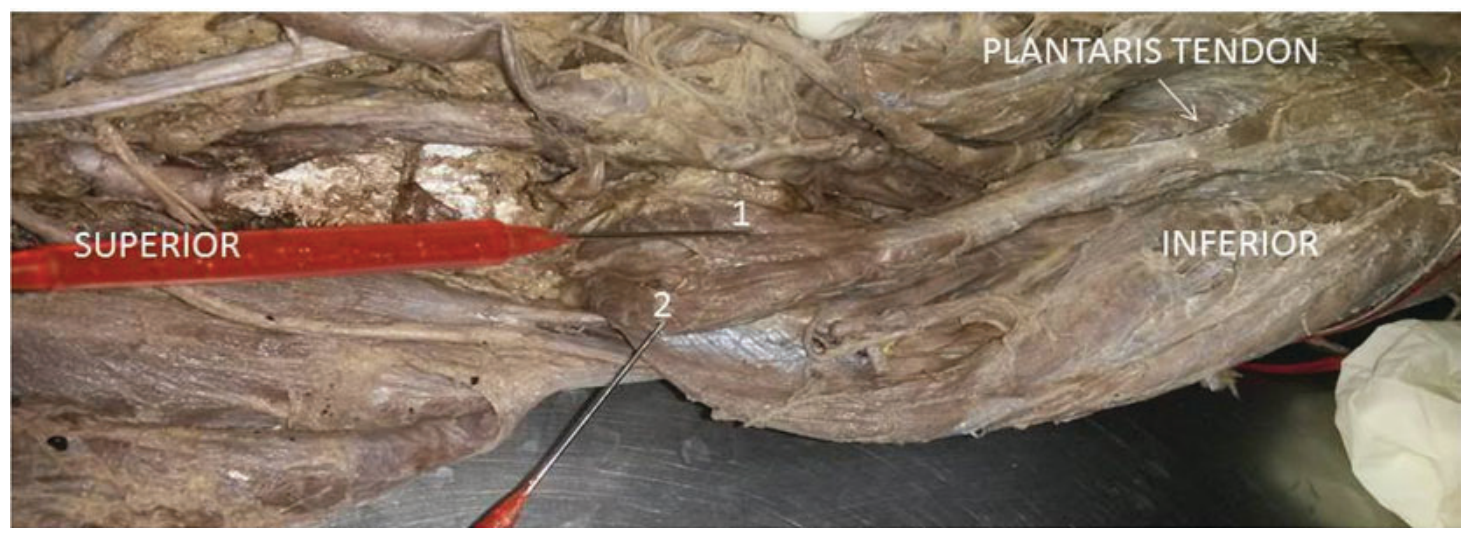

Figure 1: Dual Origin of Plantaris Muscle Belly. 


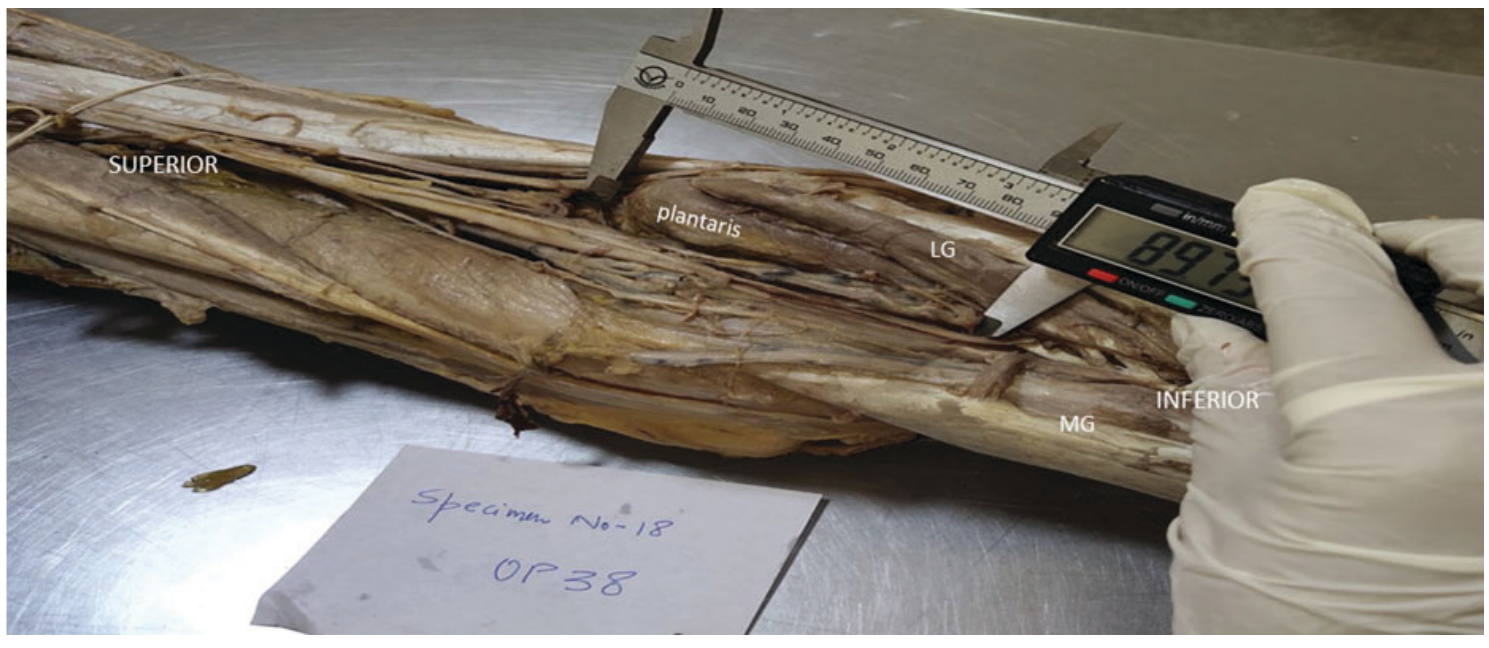

Figure 2: Plantaris muscle and Relations (MG \& LG- Medial and Lateral Gastrocnemius.

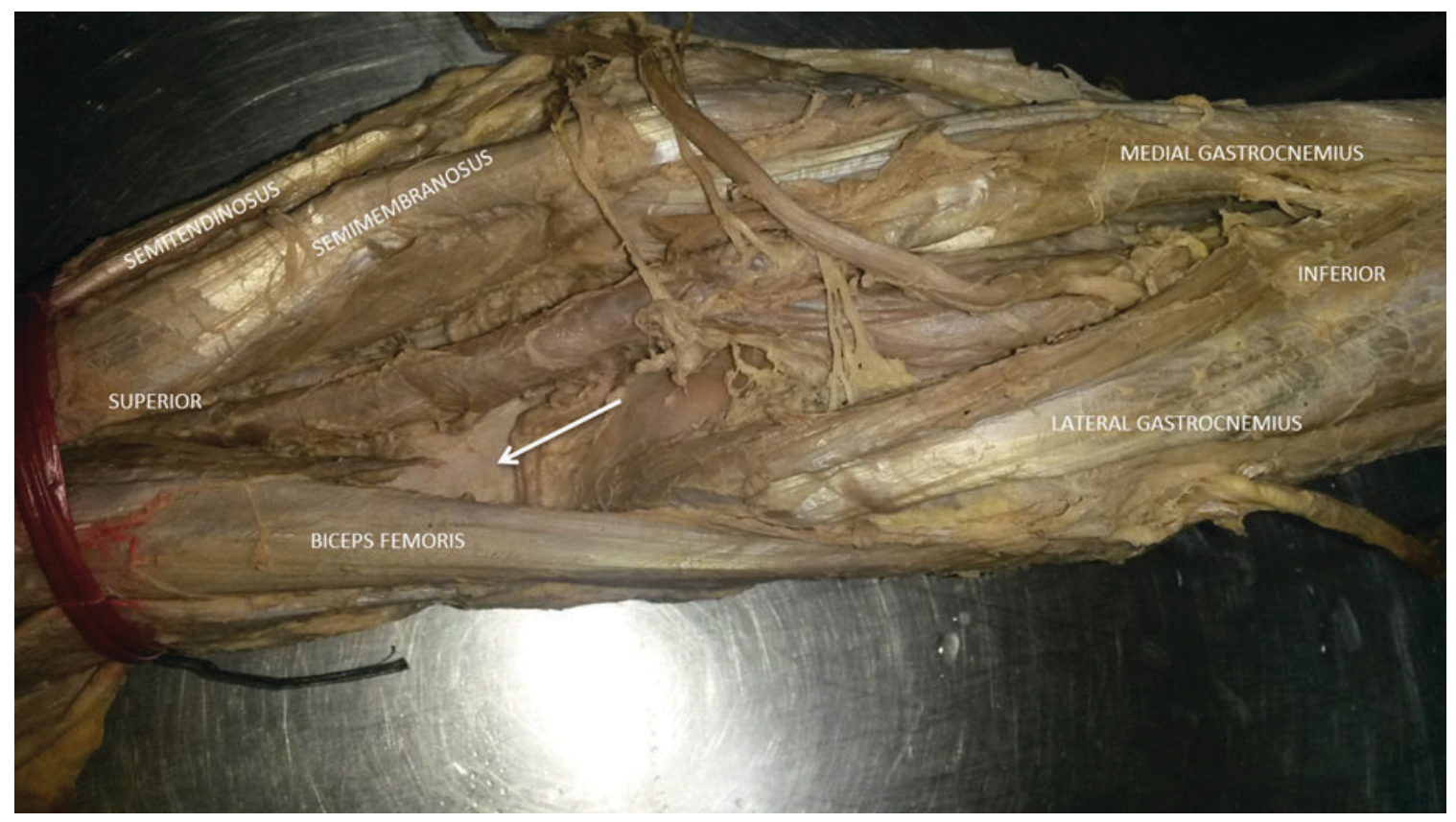

Figure 3: Absence of Plantaris Muscle. 